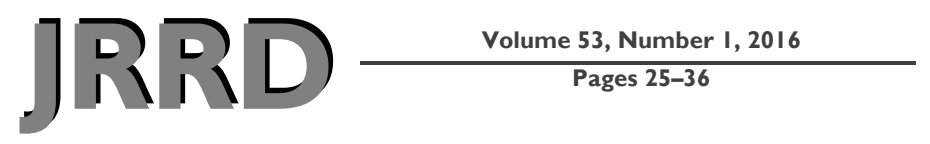

\title{
Correlates of prescription opioid therapy in Veterans with chronic pain and history of substance use disorder
}

\author{
Travis I. Lovejoy, PhD, MPH; ${ }^{1 *}$ Steven K. Dobscha, MD; ${ }^{1}$ Dennis C. Turk, PhD; ${ }^{2}$ Melissa B. Weimer, DO, \\ MCR; ${ }^{3}$ Benjamin J. Morasco, PhD $^{1}$ \\ ${ }^{1}$ Mental Health and Clinical Neurosciences Division and Center to Improve Veteran Involvement in Care, Department \\ of Veterans Affairs Portland Health Care System, Portland, OR; and Department of Psychiatry, Oregon Health and \\ Science University, Portland, OR; ${ }^{2}$ Department of Anesthesiology and Pain Medicine, University of Washington, Seat- \\ tle, WA; ${ }^{3}$ Department of Medicine, Oregon Health and Science University, Portland, OR
}

\begin{abstract}
Patients with a history of substance use disorder (SUD) are more likely to be prescribed opioid medications for chronic pain than patients without an SUD history; however, little is known about prescription opioid therapy in populations composed exclusively of patients with SUD. This study examined correlates of prescription opioid therapy in 214 Veterans with chronic noncancer pain and an SUD history. Participants completed psychosocial questionnaires and participated in a structured mental health diagnostic interview, and medical diagnoses and opioid pharmacy data were abstracted from their Department of Veterans Affairs electronic medical records. Participants were categorized into three groups based on opioid prescriptions in the past $90 \mathrm{~d}$ : no opioid therapy $(n=134)$, shortterm $(<90 \mathrm{~d})$ opioid therapy $(n=31)$, or long-term $(>/=90 \mathrm{~d})$ opioid therapy $(n=49)$. Relative to participants prescribed no or short-term opioid therapy, participants who were prescribed long-term opioid therapy had a greater number of pain diagnoses; reported higher levels of pain severity, interference, and catastrophizing; and endorsed lower chronic pain self-efficacy. In a multivariate model, number of pain diagnoses and pain interference were associated with a greater likelihood of being prescribed long-term opioid therapy after controlling for demographic and clinical characteristics. Findings highlight the poor pain-related functioning in patients with SUD histories who are prescribed long-term opioid therapy.
\end{abstract}

Key words: chronic noncancer pain, chronic pain, long-term opioid therapy, opioids, pain, pain interference, prescription opioid therapy, short-term opioid therapy, substance use disorder, Veterans.

\section{INTRODUCTION}

More than half of Department of Veterans Affairs (VA) primary care patients report pain, with many reporting chronic pain [1-3]. Relative to patients without chronic pain, patients with chronic pain have increased medical utilization, disability, and lost work productivity and decreased quality of life $[1,4-5]$. High rates of past and current alcohol and other substance use disorders (SUDs) have also been observed in patients with chronic pain [6-7].

Abbreviations: $\mathrm{ANOVA}=$ analysis of variance, $\mathrm{BDI}-\mathrm{II}=$ Beck Depression Inventory-Second Edition, DSM-IV = Diagnostic and Statistical Manual of Mental Disorders-Fourth Edition, LOT $=$ long-term opioid therapy, MPI = West Haven-Yale Multidimensional Pain Inventory, NIH = National Institutes of Health, NOT $=$ no opioid therapy, $\mathrm{PTSD}=$ posttraumatic stress disorder, $\mathrm{SD}=$ standard deviation, $\mathrm{SOT}=$ short-term opioid therapy, SUD = substance use disorder, VA = Department of Veterans Affairs.

*Address all correspondence to Travis I. Lovejoy, PhD, MPH; VA Portland Health Care System, 3710 SW U.S. Veterans Hospital Rd, R\&D 66, Portland, OR 97239; 503220-8262, ext 57744; fax: 503-273-5367.

Email: travis.lovejov@va.gov

http://dx.doi.org/10.1682/JRRD.2014.10.0230 
Prescription opioid therapy is commonly used to treat chronic pain in both Veteran and non-Veteran patients [810]. However, controversy surrounds this practice because recent studies indicate that fewer than half of patients prescribed opioids will experience a clinically significant reduction in pain intensity in the short term, with little improvement in physical function long-term [11-12]. Treating chronic pain with opioid therapy in patients with comorbid SUD may be especially difficult. Persons with chronic pain and SUD histories prescribed opioid therapy are at increased risk of opioid misuse, abuse, and diversion $[2,13]$ as well as opioid overdose and opioid-related death [14-15]. These data have contributed to further controversy over the prescription of opioids to persons with SUD [16-18].

Several studies have identified specific patient demographic and clinical characteristics associated with prescription short-term opioid therapy (SOT) and long-term opioid therapy (LOT) among diverse samples of Veterans with and without SUD histories. These include younger age, male sex, white race, mental health diagnoses (e.g., depressive disorders and posttraumatic stress disorder [PTSD]), specific pain diagnoses (e.g., low back pain, neck or joint pain, arthritis), and greater perceived pain intensity [8-9,19-20]. Notably, Veterans with comorbid chronic pain and SUD, relative to Veterans with chronic pain and no SUD, are also more likely to be prescribed SOT and LOT at high doses $[2,8,13,21-22]$. No studies, however, have identified correlates of prescription opioid therapy within samples composed exclusively of patients with lifetime SUD histories, and it is unclear whether correlates of opioid therapy identified in previous studies that recruited heterogeneous patient samples will extend to SUD populations. Furthermore, previous studies that examined correlates of prescription opioid therapy have predominantly used administrative data, limiting available data to what were included in and could be extracted from patients' medical records (e.g., demographic characteristics, medical diagnoses).

The current study examined correlates of prescription opioid therapy in VA patients with chronic pain and lifetime SUD histories using data available in patients' medical records integrated with well-validated measures of psychopathology, substance use, and pain-related variables obtained through self-report questionnaires and clinical interviews. Based on prior research, we hypothesized that patients with more severe depressive and PTSD-related symptoms, an active SUD, and poor painrelated coping and functioning would be more likely to be prescribed LOT to manage pain. We further hypothesized that these relationships would remain significant even after controlling for demographic characteristics that have been associated with prescription opioid therapy in previous studies.

\section{METHODS}

\section{Participants and Procedures}

Participants consisted of a sample from a larger study at a single VA medical center in the Pacific Northwest that examined the relationship between chronic pain, hepatitis $\mathrm{C}$ virus infection, and substance abuse [23]. Participants were recruited by posted advertisements in the medical center, letters sent to patients with scheduled primary care appointments, announcements in mental health classes, and referral by clinicians in the medical center's Hepatology Clinic. Participants completed a single research appointment consisting of a clinical interview and completion of self-administered questionnaires. They received a $\$ 30$ store gift card as compensation.

Eligible participants met the following study inclusion criteria: history of being tested for hepatitis $\mathrm{C}$ regardless of the result of the test ( $62 \%$ of enrolled participants were hepatitis $\mathrm{C}$ positive), age $18 \mathrm{yr}$ or older, and English literacy. Patients with hepatitis $\mathrm{C}$ have high rates of chronic pain [24-25] and SUD [26], making this sample ideal for examining prescription opioid therapy in patients with both chronic pain and SUD histories. A total of 375 patients were screened for study eligibility, and 284 participants enrolled in the larger study between March 2009 and August 2011. Reasons for study exclusion included age greater than $70 \mathrm{yr}(n=1)$, pending litigation or disability compensation for pain $(n=28)$, presence of advanced liver disease $(n=50)$, current suicidal ideation $(n=2)$, current untreated psychotic-spectrum disorder (e.g., schizophrenia) or bipolar disorder $(n=2)$, cognitive impairment that precluded participation $(n=2)$, being a non-Veteran $(n=3)$, and incomplete responses to eligibility screening questions $(n=3)$.

\section{Data Collection}

\section{Demographic Characteristics}

Self-administered questionnaires assessed participant demographic characteristics, including age, sex, race, marital status, years of education, and annual income. 


\section{Pain Measures}

Participants completed several well-validated and commonly used pain measures. Participants' perception of pain severity and the extent to which pain interferes with their lives was assessed with the West Haven-Yale Multidimensional Pain Inventory (MPI) severity scale (3 items) and interference scale (11 items) [27]. Pain severity and interference are widely used measures in studies of pain and have been recommended through expert consensus as core outcome measures in pain clinical trials [28]. MPI severity and interference scores range from 0 to 6 , with scores lower than 2 indicating no or mild pain severity or interference, scores between 2 and 4 indicating moderate pain severity or interference, and scores higher than 4 representing severe pain severity or interference [29]. Pain-related catastrophizing was assessed with the 13-item Pain Catastrophizing Scale [30]. The Pain Catastrophizing Scale includes items that assess exaggerated negative orientation toward pain. Self-efficacy for managing pain was assessed with the 22-item Chronic Pain Self-Efficacy Scale [31], which measures individuals' beliefs about the extent to which they can manage their pain. Items on all pain measures used in the current study use numeric rating scales, and items are summed or averaged within scales to produce scale scores.

\section{Mental Health Functioning}

The 21-item Beck Depression Inventory-Second Edition (BDI-II) [32] assessed depressive symptom severity in the past $2 \mathrm{wk}$. The PTSD Checklist-Civilian Version [33] is commonly used in VA studies that examine symptoms of PTSD and evaluates the extent to which respondents experienced each of 17 PTSD-related symptoms in the past 1 mo. We chose to use the civilian rather than military version of the PTSD Checklist in order to assess current symptoms associated with "stressful life experiences." Prior research has demonstrated good psychometric characteristics of the PTSD Checklist-Civilian Version among Veterans [34-35]. For the current study, participants were classified as meeting criteria for PTSD if they responded affirmatively to an index trauma question and scored at least 50 on the PTSD Checklist. Scores above this cutoff are indicative of clinically significant PTSD symptoms [36].

\section{Substance Use Disorders}

To obtain detailed SUD histories, trained interviewers administered the SUD module of the Structured Clinical Interview for the Diagnostic and Statistical Manual of Mental Disorders-Fourth Edition (DSM-IV) [37], which has demonstrated excellent psychometric properties [38]. This interview identifies patients' lifetime histories of alcohol and non-alcohol substance abuse and dependence that are consistent with DSM-IV diagnostic criteria. The Structured Clinical Interview was modified for the current study to allow for separate diagnoses of prescription opioid use disorder and illicit (e.g., heroin) opioid use disorder. Consistent with DSM-IV diagnostic criteria, participants who met criteria in the prior month for substance abuse or dependence were coded as having an active SUD. Participants who previously met criteria for substance abuse or dependence, but not in the past month, were coded as having a lifetime SUD history. For participants who met diagnostic criteria for a lifetime SUD history, we did not distinguish between those in early versus sustained remission or partial versus full remission. We used these definitions of active and lifetime SUD history to align with DSM-IV diagnostic criteria and because a purpose of the parent study was to identify the proportion of patients with current SUD symptoms that required clinical attention.

\section{Pain Diagnoses and Opioid Prescriptions}

Pain diagnoses and opioid pharmacy data were extracted from patients' electronic medical records using the Veterans Integrated Service Network-20 Data Warehouse. The Data Warehouse contains extracts of data from clinical records of regional VA facilities and national VA databases. Diagnostic data were obtained using International Classification of Diseases, 9th Edition, Clinical Modification codes listed in medical encounter data for the $5 \mathrm{yr}$ preceding study assessment. Pain diagnoses included neck or joint pain, low back pain, arthritis, migraine headache, neuropathy, and fibromyalgia. Electronic medical record data also identified participants who had current opioid prescriptions from this medical center. Opioid type included codeine, fentanyl, hydrocodone, hydromorphone, methadone, morphine, oxycodone, oxymorphone, and propoxyphene. Notably, no participants were prescribed methadone as part of an opioid substitution program. We abstracted data on opioid type and duration in the past $90 \mathrm{~d}$. Type of opioid prescribed was categorized into short-acting only (codeine, hydrocodone, hydromorphone, morphine, oxycodone, oxymorphone, and propoxyphene), long-acting only (fentanyl, methadone, and sustained-release hydromorphone, morphine, oxycodone, and oxymorphone), or concurrent short- and long-acting [39-40]. 


\section{Statistical Analyses}

This study included a subset of 214 participants from the larger sample who had one or more chronic pain diagnoses in the electronic medical record and met criteria for one or more active or lifetime SUDs based on the structured diagnostic interview. To identify correlates of prescription opioid therapy, we categorized participants into three groups: (1) no opioid therapy (NOT) in the past $90 \mathrm{~d}$ $(n=134)$, (2) SOT (<90 d duration; $n=31)$, or (3) LOT ( $\geq 90$ d duration; $n=49$ ). Similar definitions of SOT and LOT have been used in prior studies [8,20,41-42].

We conducted bivariate analyses using analysis of variance (ANOVA) for continuous variables and chisquare tests of association for categorical variables to compare demographic characteristics, mental health functioning, pain variables, and SUD diagnoses between the three opioid therapy groups. Significant omnibus ANOVA tests were followed with Fisher least significant difference pairwise comparisons. We also compared type of prescribed opioid between those on SOT versus LOT using chi-square tests of association. We next conducted a hierarchical multinomial logistic regression analysis to identify clinical and pain-related variables most strongly associated with NOT versus SOT versus LOT in the past $90 \mathrm{~d}$. The goal of this analysis was to test the hypothesized correlates of prescription opioid therapy. The first step of this model controlled for demographic characteristics that have demonstrated associations with receipt of prescription opioid therapy in prior studies (age, sex, race) $[8-9,19]$. In the second step, we included depres- sion symptom severity, PTSD diagnosis, and active SUD diagnosis. Data screening procedures identified high intercorrelations between five pain variables: number of pain diagnoses, pain severity, pain interference, pain catastrophizing, and chronic pain self-efficacy (see Table 1 for variable correlations). We thus performed a backward stepwise elimination procedure for the pain variables in the third step of the model, retaining variables in the model that were significant at the $p<0.10$ level. We chose this cutoff criterion to ensure retention of pain variables most strongly correlated with prescription opioid therapy while maintaining model parsimony [43]. All analyses employed two-tailed tests of significance.

\section{RESULTS}

This sample of 214 Veteran patients with chronic pain and SUD histories was composed predominantly of white (76\%) male (94\%) individuals. Of the participants, 60 percent had annual incomes less than $\$ 15,000$ and 78 percent had a high school education or greater. Nearly all participants $(95 \%)$ met diagnostic criteria for a lifetime alcohol use disorder, and many also met criteria for a lifetime cannabis use disorder (64\%), lifetime cocaine use disorder (59\%), and lifetime stimulant use disorder (54\%). Thirty-nine percent of participants met criteria for a lifetime opioid use disorder and of these, 61 percent $(n=51)$ reported prior abuse of prescription opioids. Seventeen percent of participants $(n=36)$ met criteria for

Table 1.

Bivariate correlations between demographic, clinical, and pain variables.

\begin{tabular}{|c|c|c|c|c|c|c|c|c|c|c|c|}
\hline Covariate & 1 & 2 & 3 & 4 & 5 & 6 & 7 & 8 & 9 & 10 & 11 \\
\hline \multicolumn{12}{|l|}{ Demographic } \\
\hline Sex $($ Male $=0$, Female $=1)$ & -0.11 & 1.00 & - & - & - & - & - & - & - & - & - \\
\hline \multicolumn{12}{|l|}{ Clinical } \\
\hline BDI-II Depression Severity & -0.11 & 0.04 & 0.04 & 1.00 & - & - & - & - & - & - & - \\
\hline PTSD Diagnosis $($ No $=0$, Yes,$=1)$ & -0.07 & -0.02 & 0.05 & $0.51^{*}$ & 1.00 & - & - & - & - & - & - \\
\hline No. of Pain Diagnoses & $0.15^{\dagger}$ & -0.03 & 0.01 & $0.19^{*}$ & 0.11 & -0.07 & 1.00 & - & - & - & - \\
\hline Pain Severity & 0.13 & 0.05 & -0.03 & $0.32^{*}$ & $0.21^{*}$ & 0.06 & $0.33^{*}$ & 1.00 & - & - & - \\
\hline Pain Interference & $0.15^{\dagger}$ & -0.01 & -0.01 & $0.43^{*}$ & $0.33^{*}$ & 0.08 & $0.32^{*}$ & $0.81^{*}$ & 1.00 & - & - \\
\hline Pain Catastrophizing & -0.05 & -0.01 & 0.08 & $0.57^{*}$ & $0.37^{*}$ & $0.16^{\dagger}$ & $0.24^{*}$ & $0.63^{*}$ & $0.66^{*}$ & 1.00 & - \\
\hline Chronic Pain Self-Efficacy & -0.12 & -0.01 & 0.04 & $-0.35^{*}$ & -0.12 & -0.08 & $-0.25^{*}$ & $-0.48^{*}$ & $-0.56^{*}$ & $-0.53^{*}$ & 1.00 \\
\hline
\end{tabular}


an active SUD; the most common active SUD diagnoses included alcohol $(64 \%, n=23)$ and cannabis $(22 \%, n=8)$ use disorders. Only 17 percent $(n=6)$ of participants with an active SUD met diagnostic criteria for an opioid use disorder; half of these participants $(n=3)$ met criteria for illicit opioid use disorder, while the other half $(n=3)$ met criteria for prescription opioid use disorder. Nineteen participants $(9 \%)$ were receiving specialty SUD treatment at the time of study assessment.

The most common pain syndromes in the sample were neck or joint pain (82\%), low back pain (66\%), and arthritis (57\%). Having multiple pain syndromes was the norm rather than the exception; 74 percent of participants had at least two chronic pain diagnoses, with a mean \pm standard deviation (SD) of $2.5 \pm 1.3$ pain diagnoses in the entire sample. Thirty-seven percent of participants $(n=$ 80) were prescribed opioid therapy in the past $90 \mathrm{~d}$, with 61 percent of those $(n=49)$ prescribed LOT. Among participants prescribed opioids, 85 percent were prescribed short-acting opioids only, 6 percent were prescribed long-acting opioids only, and 9 percent were prescribed both short- and long-acting opioids. The most commonly prescribed opioids were hydrocodone (65\% prescribed SOT and $61 \%$ prescribed LOT) and oxycodone $(26 \%$ prescribed SOT and $43 \%$ prescribed LOT). The mean \pm SD BDI-II score in the sample was $17.1 \pm 12.5$, with 47 percent scoring above 17 , which is representative of clinically significant depressive symptoms [32]. Of the participants, 114 (53\%) were prescribed antidepressant medication at the time of study assessment. Thirty-two percent met criteria for PTSD based on PTSD Checklist scores.

\section{Bivariate Correlates of Prescription Opioid Therapy}

Table 2 provides data comparing participants in the three groups (NOT, SOT, and LOT) on demographic characteristics, mental health variables, SUD variables, pain-related variables, and type of opioid therapy received. Difference trends in depression, receipt of antidepressant medication, and PTSD were observed across the three groups, suggesting increasing depressive symptom severity and PTSD prevalence and receipt of antidepressant medication for participants prescribed opioid therapy, particularly LOT; however, these results did not reach statistical significance. Participants prescribed LOT reported poorer pain-related function and had more pain diagnoses. Specifically, participants prescribed LOT, relative to those prescribed NOT or SOT, reported greater pain severity, pain interference, pain catastrophizing, and lower self-efficacy to manage pain. Pain severity and interference were also higher in participants prescribed SOT relative to those prescribed NOT. Participants prescribed LOT had more pain diagnoses relative to those prescribed NOT or SOT. No differences in demographic or SUD variables were observed between participants prescribed NOT, SOT, or LOT.

Notably, among the 80 participants prescribed opioid therapy in the past $90 \mathrm{~d}$, those prescribed LOT were less likely than those prescribed SOT to be prescribed shortacting opioids only ( $78 \%$ vs $97 \%, p=0.05)$. However, only 22 percent of participants prescribed LOT were prescribed long-acting opioids.

\section{Multivariate Model of Any Prescription Opioid Therapy}

A multivariate hierarchical multinomial logistic regression model identified correlates of NOT $(n=134)$ versus SOT $(n=31)$ versus LOT $(n=49)$. This model controlled for age, sex, and race in the first model step. The overall step was nonsignificant ( $\operatorname{step} 1 \chi^{2}(6)=2.06$, $p=0.91$ ), as were each of the individual demographic covariates. The second model step, which included depressive symptom severity, PTSD diagnosis, and active SUD diagnosis, was also nonsignificant (step $\left.2 \chi^{2}(6)=9.39, p=0.15\right)$, as were each of the mental health and SUD covariates. Candidate pain variables included in the stepwise elimination procedure in the final model step included number of pain diagnoses, pain severity, pain interference, pain catastrophizing, and chronic pain self-efficacy. The overall model step was significant (step $3 \chi^{2}(4)=37.98, p<0.001$ ). Only number of pain diagnoses $\left(\chi^{2}(2)=7.78, p=0.02\right)$ and pain interference $\left(\chi^{2}(2)=24.83, p<0.001\right)$ were retained in the final model. Specifically, an increased number of pain diagnoses and greater pain interference were associated with a greater likelihood of being prescribed LOT versus NOT or SOT. Number of pain diagnoses and pain interference were unrelated to the likelihood of being prescribed SOT versus NOT. Table 3 lists final model statistics.

\section{DISCUSSION}

This study examined correlates of prescription opioid therapy for chronic pain in a sample composed entirely of patients with lifetime SUD histories. More than one-third 
Table 2.

Comparison of demographic and clinical characteristics based on receipt of opioid therapy. Data presented as mean \pm standard deviation or frequency $(\%)$.

\begin{tabular}{|c|c|c|c|c|}
\hline Characteristic & $\begin{array}{l}\text { No Opioid Therapy } \\
(n=134)\end{array}$ & $\begin{array}{c}\text { Short-Term Opioid } \\
\text { Therapy }(n=31)\end{array}$ & $\begin{array}{c}\text { Long-Term Opioid } \\
\text { Therapy }(n=49)\end{array}$ & $p$-Value \\
\hline \multicolumn{5}{|l|}{ Demographic } \\
\hline Age (yr) & $54.8 \pm 8.2$ & $54.2 \pm 6.0$ & $55.3 \pm 6.4$ & 0.82 \\
\hline White & $103(76.9)$ & $24(77.4)$ & $36(73.5)$ & 0.90 \\
\hline Marital Status & & & & 0.75 \\
\hline Divorced/Separated & $71(53.0)$ & $15(48.4)$ & $20(40.8)$ & \\
\hline Widowed & $5(3.7)$ & $2(6.5)$ & $4(8.2)$ & \\
\hline High School Education or Less & $28(20.9)$ & $8(25.8)$ & $11(22.4)$ & 0.82 \\
\hline Annual Income $<\$ 15,000$ & $79(59.0)$ & $22(71.0)$ & $28(57.1)$ & 0.40 \\
\hline \multicolumn{5}{|l|}{ Mental Health } \\
\hline \multicolumn{5}{|l|}{ Lifetime SUD Diagnoses } \\
\hline Alcohol & $127(94.8)$ & $30(96.8)$ & $47(95.9)$ & 0.87 \\
\hline Cannabis & $85(63.4)$ & $21(67.7)$ & $30(61.2)$ & 0.84 \\
\hline Cocaine & $81(60.4)$ & $21(67.7)$ & $25(51.0)$ & 0.36 \\
\hline Stimulants & $72(53.7)$ & $19(61.3)$ & $24(49.0)$ & 0.56 \\
\hline Hallucinogens & $45(33.6)$ & $11(35.5)$ & $14(28.6)$ & 0.77 \\
\hline Illicit Opioids & $39(29.1)$ & $9(29.0)$ & $17(34.7)$ & 0.76 \\
\hline Prescribed Opioids & $34(25.4)$ & $8(25.8)$ & $9(18.4)$ & 0.59 \\
\hline Sedatives & $31(23.3)$ & $6(19.4)$ & $11(22.4)$ & 0.93 \\
\hline No. of Lifetime SUD Diagnoses & $3.8 \pm 2.0$ & $4.0 \pm 2.2$ & $3.6 \pm 1.9$ & 0.64 \\
\hline Active SUD Diagnosis & $19(14.1)$ & $7(22.6)$ & $10(20.4)$ & 0.38 \\
\hline Neuropathy & $13(9.7)$ & $4(12.9)$ & $5(10.2)$ & 0.87 \\
\hline Fibromyalgia & $11(8.2)^{\mathrm{a}}$ & $1(3.2)^{\mathrm{a}}$ & $9(18.4)^{b}$ & 0.05 \\
\hline No. of Pain Diagnoses & $2.3 \pm 1.2^{\mathrm{a}}$ & $2.3 \pm 1.1^{\mathrm{a}}$ & $3.1 \pm 1.2^{b}$ & $<0.01$ \\
\hline MPI Pain Severity & $2.8 \pm 1.6^{\mathrm{a}}$ & $3.4 \pm 1.4^{\mathrm{b}}$ & $4.2 \pm 1.0^{\mathrm{c}}$ & $<0.01$ \\
\hline MPI Pain Interference & $3.1 \pm 1.8^{\mathrm{a}}$ & $3.7 \pm 1.4^{\mathrm{b}}$ & $4.7 \pm 1.0^{\mathrm{c}}$ & $<0.01$ \\
\hline Chronic Pain Self-Efficacy Scale & $1,450.6 \pm 429.0^{\mathrm{a}}$ & $1,353.9 \pm 350.1^{\mathrm{a}}$ & $1,137.6 \pm 347.4^{b}$ & $<0.01$ \\
\hline Pain Catastrophizing Scale & $19.7 \pm 12.8^{\mathrm{a}}$ & $22.5 \pm 13.4^{\mathrm{a}}$ & $28.7 \pm 11.7^{\mathrm{b}}$ & $<0.01$ \\
\hline \multicolumn{5}{|l|}{ Prescribed Opioid Therapy } \\
\hline Type of Opioid & & & & 0.05 \\
\hline Short-Acting Only & NA & $30(96.8)$ & $38(77.6)$ & \\
\hline Long-Acting Only & NA & $1(3.2)$ & $4(8.2)$ & \\
\hline Both Short- and Long-Acting & NA & $0(0.0)$ & $7(14.3)$ & \\
\hline
\end{tabular}


Table 3.

Final multivariate model examining correlates of opioid therapy. Data presented as odds ratio ( $95 \%$ confidence interval).

\begin{tabular}{|c|c|c|c|}
\hline Covariate & NOT* $^{*}$ vs SOT & NOT $^{*}$ vs LOT & SOT $^{*}$ vs LOT \\
\hline \multicolumn{4}{|l|}{ Step 1: Demographic } \\
\hline Age & $0.99(0.93-1.04)$ & $0.98(0.93-1.04)$ & $0.99(0.93-1.06)$ \\
\hline Race $($ Minority $=0$, White $=1)$ & $1.09(0.42-2.86)$ & $0.98(0.41-2.34)$ & $0.90(0.29-2.75)$ \\
\hline \multicolumn{4}{|l|}{ Step 2: Clinical } \\
\hline BDI-II Depression Severity & $0.98(0.94-1.02)$ & $0.98(0.94-1.01)$ & $1.00(0.95-1.05)$ \\
\hline Active SUD Diagnosis $($ No $=0$, Yes $=1)$ & $1.56(0.79-1.40)$ & $1.59(0.60-4.24)$ & $1.02(0.31-3.36)$ \\
\hline \multicolumn{4}{|l|}{ Step 3: Pain } \\
\hline No. of Pain Diagnoses & $0.95(0.72-1.26)$ & $1.44(1.08-1.91)^{\dagger}$ & $1.51(1.06-2.15)^{\dagger}$ \\
\hline MPI Interference Scale & $1.30(0.97-1.73)$ & $2.12(1.50-3.00)^{\dagger}$ & $1.64(1.09-2.46)^{\dagger}$ \\
\hline
\end{tabular}

of participants in this sample were prescribed an opioid in the past $90 \mathrm{~d}$. This percentage is slightly lower than the approximately 50 percent identified in a national sample of patients with chronic pain diagnoses seen in the VA during fiscal years 2009 through 2011 [9], the same years in which this study was conducted. This observed difference may be an artifact of the intervals over which prescription opioid therapy were measured in the two studies (i.e., $90 \mathrm{~d}$ in the current study vs $12 \mathrm{mo}$ in the national cohort) or the potentially nonrepresentative convenience sample recruited for the current study. Notably, our sample was similar in terms of age, sex, race, and recent SUD diagnoses when compared with a nationally representative sample of 10,159 Veterans with high alcohol consumption [44], indicating the composition of our sample across these variables reflects the broader population of VA patients with SUDs. Nonetheless, additional studies using representative samples are needed that describe recent opioid prescription trends and nonopioid pain treatment use specifically in patients with lifetime SUD histories.

Our bivariate finding that participants with SUD prescribed LOT reported greater pain severity than those prescribed NOT or SOT is consistent with our hypothesis and findings from prior studies of patients with chronic pain $[8,20]$. Unfortunately, we do not have data documenting participant pain ratings prior to the initiation of opioid therapy to determine whether pain severity reduced as a result of LOT. It is possible that high pain ratings led clinicians to initiate opioid therapy for these participants. Indeed, previous studies demonstrated that patients with SUD are highly sensitive to pain and report greater pain severity relative to those without SUD [4547]. In one scenario, elevated pain ratings in this group of participants prescribed LOT may represent reductions in pain severity from even higher pain ratings observed prior to opioid therapy initiation, albeit to levels still greater than pain ratings endorsed by those not prescribed opioids. Alternatively, participants prescribed LOT may have experienced near alleviation of pain when first initiating opioid therapy but over time developed opioid tolerance or opioid-induced hyperalgesia related to the chronicity of opioid therapy, resulting in a rebound of pain [48-49]. Longitudinal studies are needed to describe pain trajectories for patients with SUD prescribed opioid therapy for chronic pain to inform clinicians about when to initiate, maintain, and discontinue opioid therapy for those with SUD histories. Ideally, these studies would capture pain intensity and pain-related function prior to opioid initiation, during the course of opioid therapy, and when applicable, following opioid discontinuation.

Several findings about the type of opioids prescribed to participants in the current study are notable. Hydrocodone and oxycodone, both short-acting opioids, were the most commonly prescribed opioids in the entire sample at 63 and 36 percent, respectively. Prescription rates did not differ between participants prescribed SOT or LOT. Only 22 percent of those prescribed LOT were prescribed 
any long-acting opioids, and nearly two-thirds of these participants prescribed long-acting opioids were prescribed a short-acting opioid concomitantly. While a historical diagnosis of SUD by itself would not preclude a patient with chronic pain from being prescribed opioid therapy, VA/Department of Defense opioid therapy guidelines recommend use of long-acting opioids for persistent pain and prescription of any opioid therapy for chronic pain only after other nonopioid analgesic pharmacotherapies and nonpharmacologic pain treatments have insufficiently improved pain-related function [50]. Of additional concern is that oxycodone and, recently, hydrocodone are schedule II controlled substances and prescriptions of these substances are associated with increased risk of opioid overdose death [51]. VA patients with SUD histories are also 2.5 times more likely than those without SUD histories to die by prescription opioid overdose [14], indicating that two of the "riskiest" opioids are being prescribed to this already high-risk group.

A unique contribution of this study was the measurement of patient-reported pain outcomes using well-validated measures not previously included- in studies of prescription opioid therapy and the integration of these data with administrative data available in patient medical records. Notably, average pain severity and interference scores for those in the LOT category fell in the "severe" range while pain severity and interference scores for those in the NOT and SOT categories fell in the "moderate" range. Participants prescribed LOT also endorsed greater pain catastrophizing and had poorer pain coping self-efficacy skills. In our multivariate analysis, pain interference remained the most robust correlate of LOT. Many patients with chronic pain will not experience sustained alleviation of pain, despite trials of analgesic pharmacotherapy and nonpharmacologic pain treatment [52-53]. The emphasis for these patients thus becomes improved quality of life through reduced pain-related disability, improved physical function, and enhanced coping skills [54]. Multifaceted, collaborative pain care approaches that are consistent with a biopsychosocial approach to pain management are needed for patients with comorbid SUD because prescription opioid therapy may be contraindicated for some and ineffective at adequately managing pain in others [55].

Results of this study should be considered in light of its limitations. First, we examined a convenience sample of VA patients from a single VA medical center in the Pacific Northwest who had been tested for hepatitis C virus infection, and despite a similar demographic composition of patients in our sample versus nationally representative samples of VA patients with SUD [44], results may not generalize to this larger population. Second, questionnaire and clinical interview data were crosssectional, and we obtained pain diagnoses, opioid and antidepressant prescription data, and specialty SUD treatment utilization retrospectively from participants' medical records. As such, causal inferences cannot be drawn from these data. Third, we included participants with a lifetime history of any SUD. Some substances when combined with opioids (e.g., alcohol, benzodiazepines) may confer greater risk of opioid-related adverse events than others (e.g., cannabis). Future studies should examine which SUDs, or combination of SUDs, moderate opioid prescribing practices. Fourth, participants with lifetime SUD histories included individuals in early and partial remission from an active SUD, and receipt of opioid therapy may differ between these individuals and those with SUD in full sustained remission. Fifth, we were unable to verify adherence to prescribed opioid therapy or whether participants obtained opioid prescriptions from non-VA sources. Sixth, we did not evaluate opioid therapy retrospectively beyond $90 \mathrm{~d}$ prior to the study assessment. As such, we were unable to assess the duration of continuous opioid therapy for those in the LOT category or determine whether participants in the NOT category had previously been prescribed opioid therapy for pain. Seventh, we did not obtain information about nonopioid pain treatment received in the $90 \mathrm{~d}$ prior to the study encounter. It is thus unclear what adjunctive services participants may have been using concurrently with, or as alternatives to, opioids to manage pain. Finally, sample size limitations may have contributed to our failure to obtain statistically significant findings for variables previously shown to be associated with opioid therapy (e.g., PTSD and active SUD diagnoses) $[8,20]$.

\section{CONCLUSIONS}

In summary, we found that among a sample of VA patients with chronic pain and lifetime SUD histories, those prescribed opioid therapy, particularly LOT, had higher pain severity and poorer pain-related function and coping. Unfortunately, little is known about the effectiveness of pain treatments for patients with SUD because pain therapy clinical trials have historically excluded 
these patients [56]. Additional research is needed to identify evidence-based pain treatments for patients with chronic pain and SUD that reduce pain and improve physical function while minimizing the deleterious consequences of substance misuse and abuse.

\section{ACKNOWLEDGMENTS}

\section{Author Contributions:}

Study concept and design: T. I. Lovejoy, B. J. Morasco, D. C. Turk. Acquisition of data: B. J. Morasco.

Analysis and interpretation of data: T. I. Lovejoy, S. K. Dobscha, D. C. Turk, M. B. Weimer, B. J. Morasco.

Drafting of manuscript: T. I. Lovejoy, B. J. Morasco.

Critical revision of manuscript for important intellectual content:

T. I. Lovejoy, S. K. Dobscha, D. C. Turk, M. B. Weimer,

B. J. Morasco.

Financial Disclosures: Dr. Turk has received research support from Endo, Johnson \& Johnson, and the National Institutes of Health (NIH) and consulting fees from Eli Lilly, Ortho-McNeill-Janssen, Pfizer, and SK LifeScience. He is also a Special Government Employee of the U.S. Food and Drug Administration. All other authors have declared that no competing interests exist.

Funding/Support: This material was based on work supported by the NIH National Institute on Drug Abuse (project DA023467) to Dr. Morasco. Dr. Lovejoy was supported by Career Development Award CDA-13-268 from VA Health Services Research and Development. Institutional Review: The VA Portland Health Care System institutional review board approved the study, and all participants provided written informed consent.

Participant Follow-Up: The authors do not plan to inform participants of the publication of this study.

Disclaimer: The contents do not represent the views of the VA or U.S. Government.

\section{REFERENCES}

1. Kerns RD, Otis J, Rosenberg R, Reid MC. Veterans' reports of pain and associations with ratings of health, health-risk behaviors, affective distress, and use of the healthcare system. J Rehabil Res Dev. 2003;40(5):371-79. [PMID:15080222] http://dx.doi.org/10.1682/JRRD.2003.09.0371

2. Seal KH, Shi Y, Cohen G, Cohen BE, Maguen S, Krebs EE, Neylan TC. Association of mental health disorders with prescription opioids and high-risk opioid use in US veterans of Iraq and Afghanistan. JAMA. 2012;307(9):940-47. [PMID:22396516] http://dx.doi.org/10.1001/jama.2012.234

3. Spelman JF, Hunt SC, Seal KH, Burgo-Black AL. Post deployment care for returning combat veterans. J Gen
Intern Med. 2012;27(9):1200-1209. [PMID:22648608] http://dx.doi.org/10.1007/s11606-012-2061-1

4. Blyth FM, March LM, Brnabic AJ, Cousins MJ. Chronic pain and frequent use of health care. Pain. 2004;111(1-2): 51-58. [PMID:15327808] http://dx.doi.org/10.1016/j.pain.2004.05.020

5. Lovejoy TI, Dobscha SK, Cavanagh R, Turk DC, Morasco BJ. Chronic pain treatment and health service utilization of veterans with hepatitis C virus infection. Pain Med. 2012; 13(11):1407-16. [PMID:22958315] http://dx.doi.org/10.1111/j.1526-4637.2012.01476.x

6. Jamison RN, Kauffman J, Katz NP. Characteristics of methadone maintenance patients with chronic pain. J Pain Symptom Manage. 2000;19(1):53-62. [PMID:10687327] http://dx.doi.org/10.1016/S0885-3924(99)00144-X

7. Johannes CB, Le TK, Zhou X, Johnston JA, Dworkin RH. The prevalence of chronic pain in United States adults: Results of an Internet-based survey. J Pain. 2010;11(11): 1230-39. [PMID:20797916] http://dx.doi.org/10.1016/j.jpain.2010.07.002

8. Dobscha SK, Morasco BJ, Duckart JP, Macey T, Deyo RA. Correlates of prescription opioid initiation and long-term opioid use in veterans with persistent pain. Clin J Pain. 2013;29(2):102-8. [PMID:23269280] http://dx.doi.org/10.1097/AJP.0b013e3182490bdb

9. Edlund MJ, Austen MA, Sullivan MD, Martin BC, Williams JS, Fortney JC, Hudson TJ. Patterns of opioid use for chronic noncancer pain in the Veterans Health Administration from 2009 to 2011. Pain. 2014;155(11):2337-43. [PMID:25180008] http://dx.doi.org/10.1016/j.pain.2014.08.033

10. Sullivan MD, Edlund MJ, Fan MY, Devries A, Brennan Braden J, Martin BC. Trends in use of opioids for non-cancer pain conditions 2000-2005 in commercial and Medicaid insurance plans: The TROUP study. Pain. 2008;138(2):440-49. [PMID:18547726] http://dx.doi.org/10.1016/j.pain.2008.04.027

11. Furlan AD, Sandoval JA, Mailis-Gagnon A, Tunks E. Opioids for chronic noncancer pain: A meta-analysis of effectiveness and side effects. CMAJ. 2006;174(11):1589-94. [PMID:16717269] http://dx.doi.org/10.1503/cmaj.051528

12. Kalso E, Edwards JE, Moore RA, McQuay HJ. Opioids in chronic non-cancer pain: Systematic review of efficacy and safety. Pain. 2004;112(3):372-80. [PMID:15561393] http://dx.doi.org/10.1016/j.pain.2004.09.019

13. Morasco BJ, Dobscha SK. Prescription medication misuse and substance use disorder in VA primary care patients with chronic pain. Gen Hosp Psychiatry. 2008;30(2):93-99. [PMID:18291290] http://dx.doi.org/10.1016/j.genhosppsych.2007.12.004 
14. Bohnert AS, Valenstein M, Bair MJ, Ganoczy D, McCarthy JF, Ilgen MA, Blow FC. Association between opioid prescribing patterns and opioid overdose-related deaths. JAMA. 2011;305(13):1315-21. [PMID:21467284] http://dx.doi.org/10.1001/jama.2011.370

15. Bohnert AS, Ilgen MA, Ignacio RV, McCarthy JF, Valenstein M, Blow FC. Risk of death from accidental overdose associated with psychiatric and substance use disorders. Am J Psychiatry. 2012;169(1):64-70. [PMID:21955932] http://dx.doi.org/10.1176/appi.ajp.2011.10101476

16. Chang YP, Compton P. Management of chronic pain with chronic opioid therapy in patients with substance use disorders. Addict Sci Clin Pract. 2013;8:21. [PMID:24341916] http://dx.doi.org/10.1186/1940-0640-8-21

17. Cheatle M, Comer D, Wunsch M, Skoufalos A, Reddy Y. Treating pain in addicted patients: Recommendations from an expert panel. Popul Health Manag. 2014;17(2):79-89. [PMID:24138341] http://dx.doi.org/10.1089/pop.2013.0041

18. Cruciani RA, Esteban S, Seewald RM, Altilio T, Bookbinder M, Sheu R, Portenoy RK. MMTP patients with chronic pain switching to pain management clinics. A problem or an acceptable practice? Pain Med. 2008;9(3): 359-64. [PMID:18366514] http://dx.doi.org/10.1111/j.1526-4637.2006.00224.x

19. Chen I, Kurz J, Pasanen M, Faselis C, Panda M, Staton LJ, O'Rorke J, Menon M, Genao I, Wood J, Mechaber AJ, Rosenberg E, Carey T, Calleson D, Cykert S. Racial differences in opioid use for chronic nonmalignant pain. J Gen Intern Med. 2005;20(7):593-98. [PMID:16050852] http://dx.doi.org/10.1007/s11606-005-0105-5

20. Macey TA, Morasco BJ, Duckart JP, Dobscha SK. Patterns and correlates of prescription opioid use in OEF/OIF veterans with chronic noncancer pain. Pain Med. 2011;12(10): 1502-9. [PMID:21899715] http://dx.doi.org/10.1111/j.1526-4637.2011.01226.x

21. Morasco BJ, Duckart JP, Carr TP, Deyo RA, Dobscha SK. Clinical characteristics of veterans prescribed high doses of opioid medications for chronic non-cancer pain. Pain. 2010; 151(3):625-32. [PMID:20801580] http://dx.doi.org/10.1016/j.pain.2010.08.002

22. Morasco BJ, Duckart JP, Dobscha SK. Adherence to clinical guidelines for opioid therapy for chronic pain in patients with substance use disorder. J Gen Intern Med. 2011;26(9): 965-71. [PMID:21562923] http://dx.doi.org/10.1007/s11606-011-1734-5

23. Morasco BJ, Lovejoy TI, Turk DC, Crain A, Hauser P, Dobscha SK. Biopsychosocial factors associated with pain in veterans with the hepatitis C virus. J Behav Med. 2014; 37(5):902-11. [PMID:24338521] http://dx.doi.org/10.1007/s10865-013-9549-y
24. Morasco BJ, Huckans M, Loftis JM, Woodhouse J, Seelye A, Turk DC, Hauser P. Predictors of pain intensity and pain functioning in patients with the hepatitis $\mathrm{C}$ virus. Gen Hosp Psychiatry. 2010;32(4):413-18. [PMID:20633746] http://dx.doi.org/10.1016/j.genhosppsych.2010.03.010

25. Whitehead AJ, Dobscha SK, Morasco BJ, Ruimy S, Bussell C, Hauser P. Pain, substance use disorders and opioid analgesic prescription patterns in veterans with hepatitis $\mathrm{C}$. J Pain Symptom Manage. 2008;36(1):39-45. [PMID:18358690] http://dx.doi.org/10.1016/j.jpainsymman.2007.08.013

26. Huckans MS, Blackwell AD, Harms TA, Indest DW, Hauser P. Integrated hepatitis $C$ virus treatment: Addressing comorbid substance use disorders and HIV infection. AIDS. 2005;19(Suppl 3):S106-15. [PMID:16251805] http://dx.doi.org/10.1097/01.aids.0000192078.49185.b0

27. Kerns RD, Turk DC, Rudy TE. The West Haven-Yale Multidimensional Pain Inventory (WHYMPI). Pain. 1985; 23(4):345-56. [PMID:4088697]

http://dx.doi.org/10.1016/0304-3959(85)90004-1

28. Turk DC, Dworkin RH, Allen RR, Bellamy N, Brandenburg N, Carr DB, Cleeland C, Dionne R, Farrar JT, Galer BS, Hewitt DJ, Jadad AR, Katz NP, Kramer LD, Manning DC, McCormick CG, McDermott MP, McGrath P, Quessy S, Rappaport BA, Robinson JP, Royal MA, Simon L, Stauffer JW, Stein W, Tollett J, Witter J. Core outcome domains for chronic pain clinical trials: IMMPACT recommendations. Pain. 2003;106(3):337-45. [PMID:14659516] http://dx.doi.org/10.1016/j.pain.2003.08.001

29. Lovejoy TI, Turk DC, Morasco BJ. Evaluation of the psychometric properties of the revised short-form McGill Pain Questionnaire. J Pain. 2012;13(12):1250-57. [PMID:23182230] http://dx.doi.org/10.1016/j.jpain.2012.09.011

30. Sullivan MJ, Bishop SR, Pivik J. The Pain Catastrophizing Scale: Development and validation. Psychol Assess. 1995; 7(4):524-32. http://dx.doi.org/10.1037/1040-3590.7.4.524

31. Anderson KO, Dowds BN, Pelletz RE, Edwards WT, Peeters-Asdourian C. Development and initial validation of a scale to measure self-efficacy beliefs in patients with chronic pain. Pain. 1995;63(1):77-84. [PMID:8577493] http://dx.doi.org/10.1016/0304-3959(95)00021-J

32. Beck AT, Steer RA, Brown GK. BDI-II, Beck Depression Inventory: Manual. 2nd ed. San Antonio (TX): Psychological Corporation; 1996.

33. Weathers FW, Ford J. Psychometric properties of the PTSD Checklist (PCL-C, PCL-S, PCL-M, PCL-PR). In: Stamm $\mathrm{BH}$, editor. Measurement of stress, trauma, and adaptation. Lutherville (MD): Sidran Press; 1996. p. 250-52.

34. Dobie DJ, Kivlahan DR, Maynard C, Bush KR, McFall M, Epler AJ, Bradley KA. Screening for post-traumatic stress 
disorder in female Veteran's Affairs patients: Validation of the PTSD checklist. Gen Hosp Psychiatry. 2002;24(6): 367-74. [PMID:12490337] http://dx.doi.org/10.1016/S0163-8343(02)00207-4

35. Keen SM, Kutter CJ, Niles BL, Krinsley KE. Psychometric properties of PTSD Checklist in sample of male veterans. J Rehabil Res Dev. 2008;45(3):465-74. [PMID:18629754] http://dx.doi.org/10.1682/JRRD.2007.09.0138

36. Weathers F, Litz B, Herman D, Huska J, Keane T. The PTSD Checklist (PCL): Reliability, validity, and diagnostic utility. Proceedings of the International Society for Traumatic Stress Studies Annual Meeting; 1993 Oct; San Antonio, TX.

37. First MB, Spitzer RL, Gibbon M, Williams JB. Structured clinical interview for the DSM-IV-TR axis I disorders, research version, non-patient edition (SCID-I/NP). New York (NY): New York State Psychiatric Institute; 2002.

38. Segal DL. Structured interviewing in DSM classification. In: Turner SM, Hersen M, editors. Adult psychopathology and diagnosis. 3rd ed. New York (NY): Wiley; 1997. p. 24-57.

39. Argoff CE, Silvershein DI. A comparison of long- and short-acting opioids for the treatment of chronic noncancer pain: Tailoring therapy to meet patient needs. Mayo Clin Proc. 2009;84(7):602-12. [PMID:19567714] http://dx.doi.org/10.1016/S0025-6196(11)60749-0

40. Fine PG, Mahajan G, McPherson ML. Long-acting opioids and short-acting opioids: Appropriate use in chronic pain management. Pain Med. 2009;10(Suppl 2):S79-88. [PMID:19691687] http://dx.doi.org/10.1111/j.1526-4637.2009.00666.x

41. Edlund MJ, Sullivan M, Steffick D, Harris KM, Wells KB. Do users of regularly prescribed opioids have higher rates of substance use problems than nonusers? Pain Med. 2007; 8(8):647-56. [PMID:18028043] http://dx.doi.org/10.1111/j.1526-4637.2006.00200.x

42. Von Korff M, Saunders K, Thomas Ray G, Boudreau D, Campbell C, Merrill J, Sullivan MD, Rutter CM, Silverberg MJ, Banta-Green C, Weisner C. De facto long-term opioid therapy for noncancer pain. Clin J Pain. 2008; 24(6):521-27. [PMID:18574361]

http://dx.doi.org/10.1097/AJP.0b013e318169d03b

43. Hosmer DW, Lemshow S. Applied logistic regression. New York (NY): Wiley; 1989.

44. Glass JE, Perron BE, Ilgen MA, Chermack ST, Ratliff S, Zivin K. Prevalence and correlates of specialty substance use disorder treatment for Department of Veterans Affairs Healthcare System patients with high alcohol consumption. Drug Alcohol Depend. 2010;112(1-2):150-55.

[PMID:20656425]

http://dx.doi.org/10.1016/j.drugalcdep.2010.06.003

45. Egli M, Koob GF, Edwards S. Alcohol dependence as a chronic pain disorder. Neurosci Biobehav Rev. 2012;36(10):

\section{9-92. [PMID:22975446]}

http://dx.doi.org/10.1016/j.neubiorev.2012.07.010

46. Treister R, Eisenberg E, Lawental E, Pud D. Is opioidinduced hyperalgesia reversible? A study on active and former opioid addicts and drug naïve controls. J Opioid Manag. 2012;8(6):343-49. [PMID:23264312]

http://dx.doi.org/10.5055/jom.2012.0134

47. Wallace M, Schulteis G, Atkinson JH, Wolfson T, Lazzaretto D, Bentley H, Gouaux B, Abramson I. Dose-dependent effects of smoked cannabis on capsaicin-induced pain and hyperalgesia in healthy volunteers. Anesthesiology. 2007; 107(5):785-96. [PMID:18073554] http://dx.doi.org/10.1097/01.anes.0000286986.92475.b7

48. Brush DE. Complications of long-term opioid therapy for management of chronic pain: The paradox of opioidinduced hyperalgesia. J Med Toxicol. 2012;8(4):387-92. [PMID:22983894] http://dx.doi.org/10.1007/s13181-012-0260-0

49. Raffa RB, Pergolizzi JV Jr. Opioid-induced hyperalgesia: Is it clinically relevant for the treatment of pain patients? Pain Manag Nurs. 2013;14(3):e67-83. [PMID:23972873] http://dx.doi.org/10.1016/j.pmn.2011.04.002

50. The Management of Opioid Therapy for Chronic Pain Working Group. VA/DoD clinical practice guideline for management of opioid therapy for chronic pain. Washington (DC): The Office of Quality and Performance, VA \& Quality Management Division, U.S. Army MEDCOM; 2010.

51. Hirsch A, Proescholdbell SK, Bronson W, Dasgupta N. Prescription histories and dose strengths associated with overdose deaths. Pain Med. 2014;15(7):1187-95.

[PMID:25202775]

http://dx.doi.org/10.1111/pme.12391

52. Karttunen NM, Turunen JH, Ahonen RS, Hartikainen SA. Persistence of noncancer-related musculoskeletal chronic pain among community-dwelling older people: A population-based longitudinal study in Finland. Clin J Pain. 2015; 31(1):79-85. [PMID:24577431] http://dx.doi.org/10.1097/AJP.0000000000000089

53. Knook LM, Lijmer JG, Konijnenberg AY, Taminiau B, van Engeland H. The course of chronic pain with and without psychiatric disorders: A 6-year follow-up study from childhood to adolescence and young adulthood. J Clin Psychiatry. 2012;73(1):e134-39. [PMID:22316584]

http://dx.doi.org/10.4088/JCP.10m06751

54. Tseng AS, Weiss K, Harrison T, Hansen D, Bruce B. Pain relief as a primary treatment goal: At what point does functioning and well-being become more important? A case study of an adolescent with debilitating chronic pain. Pain Res Manag. 2014;19(4):219-23. [PMID:24712020]

55. Morasco BJ, Corson K, Turk DC, Dobscha SK. Association between substance use disorder status and pain-related function following 12 months of treatment in primary care 
patients with musculoskeletal pain. J Pain. 2011;12(3): 352-59. [PMID:20851057]

http://dx.doi.org/10.1016/j.jpain.2010.07.010

56. Morasco BJ, Gritzner S, Lewis L, Oldham R, Turk DC, Dobscha SK. Systematic review of prevalence, correlates, and treatment outcomes for chronic non-cancer pain in patients with comorbid substance use disorder. Pain. 2011; 152(3):488-97. [PMID:21185119]

http://dx.doi.org/10.1016/j.pain.2010.10.009

Submitted for publication October 8, 2014. Accepted in revised form March 3, 2015.
This article and any supplementary material should be cited as follows:

Lovejoy TI, Dobscha SK, Turk DC, Weimer MB, Morasco BJ. Correlates of prescription opioid therapy in Veterans with chronic pain and history of substance use disorder. J Rehabil Res Dev. 2016;53(1):25-36.

http://dx.doi.org/10.1682/JRRD.2014.10.0230 